\title{
O QUE SE PODE APRENDER NUMA AULA DE MATEMÁTICA?
}

Alexandrina Monteiro*

Sílvio Gallo**

\begin{abstract}
RESUMO: Esse texto defende que uma aula de matemática não deve ser reduzida a definições, exercícios, modelos de resolução já instituídos. Consideramos a aula de matemática como um lócus possível para a produção de momentos diferenciais, momentos de inspiração que permitam aos estudantes e a nós (professores), pensar no ainda não pensado. Pensar de modos outros. Diante disso, e inspirados pelo pensamento do filósofo Gilles Deleuze, temos nesse texto por objetivo discutir as questões: quais seriam os movimentos, os ritmos possíveis de uma aula de matemática? Como poderia uma aula funcionar como disparador ao exercício do pensamento que rompa com a imagem de pensamento representacional que funda e estrutura tanto os currículos disciplinares quantos as próprias disciplinas? Nesse sentido o texto está dividido em duas partes. Numa primeira abordamos aspectos referentes ao ensino de matemática e num segundo momento apresentamos duas cenas, com o objetivo apenas de provocar nossa função docente. Por fim entendemos que as contribuições de Deleuze, além de desdobramentos propostos por outros autores, nos permitem destacar que os desvios, provocados por uma educação menor e militante, podem abrir espaços potentes para fazer o pensamento funcionar de outros modos, abrir possibilidades para novos encontros numa aula de matemática.
\end{abstract}

PALAVRAS-CHAVE: Educação matemática menor, aula de matemática, filosofia da diferença, educação menor.

\section{WHAT CAN ONE LEARN IN A MATHEMATICS CLASS?}

\begin{abstract}
This text argues that a mathematics class should not be reduced to definitions, exercises, models of resolution already in place. We consider the mathematics class as a possible locus for the production of differential moments, moments of inspiration that allow both students and us (teachers) to think about the not-yet-thoughton. Thinking in other ways. Given this, and inspired by the thought of the philosopher Gilles Deleuze we aim in this text to discuss the questions: what would be the movements, the possible rhythms of a mathematics class? How could a class act as a trigger for the exercise of thought that breaks with the image of representational thought that founds and structures both the disciplinary curricula and the disciplines themselves? In this sense, the text is divided into two parts. In the first, we approach aspects related to the teaching of mathematics and, in a second moment, we present two scenes with the sole purpose of provoking our teaching function. Finally, we understand that Deleuze's contributions, in addition to developments proposed by other authors, provoked by the deviations caused by a lesser and militant education can open powerful spaces to make thinking work in other ways, opening possibilities for new encounters in a mathematics class.
\end{abstract}

KEYWORD: minor mathematics education, mathematics class, philosophy of difference, minor education.

\footnotetext{
* Doutora em Educação. Professora da Faculdade de Educação da Unicamp. E-mail: alemath@,unicamp.br Orcid: https://orcid.org/0000-0002-5803-1358

** Livre-Docente em Filosofia da Educação. Professor Titular da Faculdade de Educação da Unicamp e pesquisador bolsista produtividade do CNPq. E-mail: gallo@,unicamp.br

Orcid: https://orcid.org/0000-0003-2221-5160
} 
Todo dia ela faz tudo sempre igual Me sacode às seis horas da manhã Me sorri um sorriso pontual E me beija com a boca de hortelã (Cotidiano. Chico Buarque. 1971).

O cotidiano escolar, muitas vezes, pode se parecer com a música de Chico Buarque. Uma música que com sua toada cíclica tende a pontuar uma relação marcada pelo machismo do marido que tudo espera da mulher submissa, inclusive a mudança no relacionamento dos dois, ou pela opressão de um governo que nos cala com uma colher de feijão, com a satisfação das condições mínimas de sobrevivência. Do mesmo modo, uma aula pode compor esse cotidiano cíclico, na qual a formatação do pensar científico-pedagógico, que prima por uma verdade suprema, leva-nos a perder o prazer da relação estabelecida e, muitas vezes, como um marido machista, esperamos dos alunos uma mudança. Como? Talvez esperando que eles adequem seus corpos e suas vidas aos nossos desejos docentes.

$\mathrm{Na}$ escola, a repetição de um cotidiano com sorrisos pontuais pode - é o que vamos defender aqui - ser rompido por variações, por intensidades de relações que precisam reexistir. É nesse sentido que nos propomos a discutir sobre o que se pode aprender numa aula de matemática a partir de contribuições deleuzianas. Seguindo esse filósofo, propomos pensar em uma aula como algo que:

“[...] não tem como objetivo ser entendida totalmente. Uma aula é uma espécie de matéria em movimento. É por isso que é musical. Numa aula, cada grupo ou cada estudante pega o que lhe convém. Uma aula ruim é a que não convém a ninguém. Não podemos dizer que tudo convém a todos. As pessoas têm de esperar. (Deleuze, 1995, p.59).

Considerando as provocações de Deleuze, qual seria o movimento, o ritmo de uma aula de matemática? Provavelmente muitos diriam que bem próxima da toada cíclica da música buarqueana anteriormente citada, ou seja: Todo dia ele/ela far tudo sempre igual; Apaga a lousa e escreve/explica o conceito/definição. Nos dá um sorriso e resolve um exercício como exemplo. E nos indica uma lista de exercícios semelhantes para resolvermos. Mas o que aprendemos com isso? O que se pode aprender numa aula de matemática?

Em seu depoimento, Deleuze segue nos alertando para ficarmos atentos a nossa capacidade de ouvir, de sentir, de captar os fluxos, as intensidades, as variações. É necessário nos emocionar, diz o filósofo: Uma aula é emoção. É tanto emoção quanto inteligência. Sem emoção, não há nada, não há interesse algum. (Deleuze, 1995, p.59).

No entanto, o que nos emociona? Que emoção há ou pode haver numa aula de matemática? Afinal, trata-se da sala de aula de matemática! O que pode uma aula de matemática? Essa é a questão que hoje nos atravessa e nos faz pensar. Não um pensamento de busca salvacionista, focado em métodos, mas um exercício de pensamento que nos inquieta, que nos provoca a pensar sobre a própria matemática e sobre seus sentidos. E, claro, muito do que exploramos aqui em torno da matemática poderia também ser deslocado para outras disciplinas escolares... 
Em um discurso que quase se aproxima do senso comum, a professora Suely Druck, em 2005, na época, presidente da Sociedade Brasileira de Matemática (SBM), comenta sobre a importância de "motivarmos" os estudantes com questões interessantes. Segundo Druck, o "bom” professor seria aquele que domina o conhecimento matemático. Ao ser inquerida se a [alta] qualidade da pesquisa em matemática tem se refletido no seu ensino ela respondeu:

Infelizmente não! Atualmente no Brasil, pesquisa e ensino em matemática compõem mundos distintos e distanciados. O primeiro cumpre com competência o seu papel de produzir conhecimento e formar recursos humanos para pesquisa. Já o segundo vem cumprindo muito mal o seu papel de transferir conhecimento e formar cidadãos, e ainda se debate com questões primárias e até surrealistas que dizem respeito à sua missão. [...] A política de descaso com a educação no país afastou muitos profissionais com boa formação matemática das questões do ensino da disciplina. Parte importante deste espaço foi ocupada por grupos que, por falta de boa formação matemática, não se debruçaram sobre o ensino da matemática de forma consistente. [...] Assim, as diretrizes que têm orientado o ensino da matemática nas últimas décadas vêm sendo formuladas sem o necessário suporte de conteúdo matemático. [...]. A dificuldade dos estudantes com a matemática ocorre em todo o mundo em virtude das características da própria disciplina. Inicialmente porque ela é sequencial, e além disso, aprender matemática requer alguma disciplina e algum esforço, e isso nem sempre é fácil de se conseguir com crianças. (DRUK, 2005, p.6. Destaques nossos).

Inicialmente percebe-se nessa resposta uma desqualificação em relação aos que se dedicam à educação matemática, alegando que as pessoas mais qualificadas matematicamente têm se afastado da docência. Aqui é necessário destacar que além da SBM, a Sociedade Brasileira de Educação Matemática (SBEm) já existia, estava bem consolidada e tecia muitas críticas a um ensino de matemática conteudista que, centrado em técnicas, apresentava altos índices de reprovação. Isso não foi sequer considerado pela autora citada.

Porém, essa compreensão da matemática conteudista parece fazer certo eco junto à sociedade, por isso a consideramos próxima ao senso comum. Essa construção discursiva do ensino e aprendizagem da matemática é sustentada por uma outra verdade, que cerca as impressões sobre essa disciplina; tratase da teoria do “dom". Segundo essa professora, para alguém descobrir se possui o "dom” para a matemática, é necessário ter "bons professores, uma vez que para aprender matemática basta gostar, o que requer disciplina e esforço, e isso nem sempre é fácil de se conseguir com crianças” (DRUK, 2005, p.6).

Nesse sentido Druk (2019) destaca que as olimpíadas de matemática são uma ótima estratégia para que alunos descubram esse "gosto". Através da Olimpíada, diz a professora, "pode acontecer que mesmo aqueles que têm dificuldade com matemática, a prática de estudar em grupo passem a gostar o que já é um grande ganho para o aluno”.

A Olimpíada Brasileira de Matemática das Escolas Públicas e privadas brasileiras (OBMEP) é realizado pelo Instituto de Matemática Pura e Aplicada (IMPA), com apoio da Sociedade Brasileira de 
Matemática (SBM), e promovida com recursos do Ministério da Educação, Ciência, Tecnologia, Inovações e Comunicações (MCTIC). As provas são impressas e aplicadas em todo o país. Organizada por etapas, alguns estudantes recebem medalhas de acordo com seu rendimento. Essas medalhas podem ser de ouro, prata, bronze e menção honrosa. Entretanto, poucos são considerados medalhistas e somente os que recebem medalhas de ouro, prata e bronze estaduais é que têm apoio que extrapolam as medalhas, como cursos, bolsas de estudo ou a possibilidade de ingressar na Universidade pública sem realizar vestibular - como ocorre na Universidade Estadual de Campinas desde 2019.

Conforme dados apresentados pelo site oficial da OBMEP ${ }^{1}$ em 2019, participaram da olimpíada: 54.831 cidades, atingindo 99,71\% dos municípios brasileiros com um total de 18.158 .775 participantes, o que coloca o Brasil como o país com o maior número de participantes nesse tipo de olimpíada². Desse total, considerando todas as fases, apenas 0,3\% receberam medalhas com a seguinte distribuição: 0,003\% (579) foram de ouro, 0,01 (1.746) foram de prata, 0,03 (5.183) foram de bronze e 0,3\% foram menção honrosa.

Considerando-se a abrangência da OBEMP e os princípios que a fundamentam ${ }^{3}-$ dentre eles destacar talentos e garantir o ensino de um determinado tipo de pensamento matemático conforme expresso pelas declarações da professora Sueli Druk anteriormente citadas, percebemos que é forte a disseminação de verdades e valores que consideram que bons professores de matemática devem ter acima de tudo uma excelente formação matemática. Nada contra. Porém, o que significa essa excelente formação matemática?

Na perspectiva da presidente da SBM essa formação, o “dom” para ser matemático e talvez professor é que fazem a diferença. É dentro desse discurso por vezes simplista que muitos ingressantes das licenciaturas iniciam seus cursos. Ou seja, pautados na crença de que por gostarem de matemática e por aprender essa ciência com profundidade, tendo acesso a bons materiais e técnicas didáticopedagógicas, isso fará deles excelentes professores. Essa perspectiva resume e reduz a "função-educador" (Carvalho, 2014) ${ }^{4}$ ao tecnicismo simplista e coloca acento à prática docente relacionada ao "gosto" e ao “dom” pela matemática.

\footnotetext{
${ }^{1}$ http://www.obmep.org.br/ acesso em 31 de março de 2021.

${ }^{2}$ Cabe ressaltar que professores e alunos premiados com as medalhas de ouro prata ou bronze recebem, além das medalhas ganhos em dinheiro e cursos no IMPA-RJ. A reportagem da Fundação de ampara o Pesquisa do Maranhão de 2018 indica que o professor da estudante ganhadora da medalha de bronze recebeu além da certificação de reconhecimento, um kit com seis livros, curso de aperfeiçoamento no IMPA, na cidade do Rio de Janeiro. Com tudo pago. [...] A estudante, por sua vez além da medalha de bronze, ganhou um certificado e uma bolsa de estudo na área da Matemática Aplicada, com um auxílio de mil e duzentos reais. [...] https://www.fapema.br/professor-e-estudantes-da-rede-municipal-sao-premiados-na-olimpiadabrasileira-de-matematica/ acesso em 23 de março de 2021.

${ }^{3}$ Contribuir para a melhoria da qualidade da educação básica, possibilitando que um maior número de alunos brasileiros possa ter acesso a material didático de qualidade, material este disponível no site, o qual inclui as questões da prova e apostilas temáticas; Identificar jovens talentos e incentivar seu ingresso em universidades, nas áreas científicas e tecnológicas; Incentivar o aperfeiçoamento dos professores das escolas públicas, contribuindo para a sua valorização profissional; Contribuir para a integração das escolas brasileiras com as universidades públicas, os institutos de pesquisa e com as sociedades científicas; Promover a inclusão social por meio da difusão do conhecimento. In http://www.obmep.org.br/ acesso em 31 de março de 2021.

${ }^{4}$ A partir da noção de "função-autor" proposta por Michel Foucault, Alexandre Filordi de Carvalho convoca a pensar uma
} 
Seria injusto da nossa parte não destacar que existem diversas outras pesquisas e propostas que são realizadas por aqueles que se vinculam a uma perspectiva de ensino e de currículo que defendem, dentre outros aspectos, a necessidade de ampliar a formação política e epistemológica dos docentes, Esse currículo, inclui questões de ordens históricas e filosóficas, considerando, assim, que a formação do professor - e em especial do professor de matemática - abrange diversos campos, não só dos conteúdos matemáticos, bem como não consideram as questões pedagógicas como meras técnicas a serem reproduzidas. Ademais, a amplitude das pesquisas na educação e no ensino de matemática está muito além das limitações de um artigo.

Nosso propósito até aqui foi o de destacar duas perspectivas: a que defende que o saber matemático associado ao "dom" e ao "gosto" promove boas experiências com a matemática e outra que não acredita que a capacidade de aprender matemática esteja associada ao dom. Entretanto, essas propostas aparentemente antagônicas, com seus contrastes, estão longe de serem consideradas dialeticamente contrárias e, precisam ser percebidas como diferenças que explodem em propostas e pesquisas das mais variadas ordens, as quais podem aproximá-las e algumas vezes distanciá-las. Por essa razão faz-se necessário ao menos pontuar aspectos dessas divergências. E, apesar de suas variações, é certo - e pensamos que muitos concordam - que desejar, gostar é algo fundamental para a docência. Não se trata de gostar de como ensinamos, de nos maravilharmos com o que fazemos, mas de gostar e de desejar aquilo que nos captura e nos mobiliza a pensar.

É nesse sentido que nos interessa pensar sobre a aula de matemática aqui. Pensar, assim, sobre uma aula que se amplifica e nos desafia a buscar por novos fluxos, e longe de buscar um discurso de contraposição, ou de crítica aos modos tecnicistas ou não de se compreender o ensino de matemática. Interessa-nos aqui pensar sobre os desvios, e as variações que escapam, mesmo quando o cotidiano se esforça para repetir e fazer da aula uma mesma e "boa" aula.

E é diante desse cenário que retomamos nossa pergunta, agora multiplicada: O que pode uma aula? O que se pode aprender em uma aula de matemática a partir de reflexões deleuzianas? O que nos emociona em uma aula de matemática? Que efeitos as cadências podem produzir? Se aula é vida, entoamos com Ataulfo Alves: Eu quero morrer numa batucada de bamba / Na cadência bonita do samba. Quais cadências podem ser produzidas numa aula?

Uma aula se inicia muito antes de adentrarmos em uma escola, numa sala de aula. Para além da noção de planos de aulas, Deleuze, em sua entrevista a Parnet, organizada na forma de um abecedário, tendo como referência a letra "P" nos fala sobre sua experiência de professor sobre a experiência de se preparar para uma aula. Afirmou ele:

Eu gostava muito de dar aula, [...]. Acho que as aulas têm equivalentes em outras áreas. Uma aula é algo que é muito preparado. Se você quer 5 minutos, 10 minutos de inspiração, tem de fazer uma longa preparação. Para ter esse momento de... Se não

\footnotetext{
"função-educador", que ajudaria a compreender a atividade docente, a forma como um professor se faz sujeito no trato com
} os estudantes. 
temos...[...]. Eu me preparava muito para ter esses momentos de inspiração. Com o passar do tempo, percebi que precisava de uma preparação crescentemente maior para obter uma inspiração cada vez menor. Então estava na hora de parar. (DELEUZE, PARNET, 1995, p.75).

Deleuze acrescenta que uma aula deve ser ensaiada. Como no teatro. "Se não tivermos ensaiado o bastante, não estaremos inspirados. Uma aula quer dizer momentos de inspiração, senão não quer dizer nada". Parnet o indaga, perguntando se o filósofo faz esse ensaio em frente ao espelho. E ele complementa:

Não, cada atividade tem seus modos de inspiração. [...] Se o orador não acha interessante o que está dizendo... Nem sempre achamos interessante o que dizemos. [...] É preciso achar a matéria da qual tratamos, a matéria que abraçamos, fascinante. Às vezes, temos de nos açoitar. Não que seja desinteressante, a questão não é essa. É necessário chegar ao ponto de falar de algo com entusiasmo. O ensaio é isso. DELEUZE, PARNET, 1995, p.76).

Assim, voltamos à nossa aula de matemática. O que faz dela algo fascinante? Algo que nos entusiasme? Claro que aqui podem ser os mais variados fatores, mas, é necessário reconhecer que não há entusiasmo sem nos encharcarmos dos saberes que pretendemos discutir, como afirma Deleuze: "É preciso estar totalmente impregnado do assunto e amar o assunto do qual falamos. Isso não acontece sozinho. É preciso ensaiar, preparar”. Então, do que se trata uma aula de matemática? Partimos do pressuposto deleuziano de que "uma aula não como objetivo ser entendida totalmente. Uma aula é uma espécie de matéria em movimento. É por isso que é musical. Numa aula cada grupo ou cada estudante pega o que lhe convém”. DELEUZE, PARNET, 1995, p.75).

Nesse sentido, entendemos que uma aula de matemática não deve se reduzir a definições, exercícios modelos e resolução de longas listas de exercício com o objetivo de fixar procedimentos de resolução já instituídos. Considerar a aula de matemática na perspectiva do entusiasmo, da perspectiva de produzir momentos diferenciais, momentos de inspiração, deve ser uma aula que permita aos estudantes e a nós (professores), pensar no ainda não pensado. Pensar de modos outros.

Acima de tudo é necessário poder pensar e poder pensar diferente. Mas o que significa pensar? Quais questões seriam capazes de mobilizar o pensamento matemático? Pode uma aula funcionar como disparador ao exercício do pensamento que rompa com a imagem de pensamento representacional que funda e estrutura tanto os currículos disciplinares quantos as próprias disciplinas? Mas o que significa romper com essa imagem representacional?

Deleuze, em Diferença e Repetição, num subitem intitulado O que é decisivo no problema da diferença: o simulacro, a resistência do simulacro, se propõe a realizar esse exercício de desconstrução da imagem de pensamento representacional e faz isso de forma radical. Segundo ele, "todo platonismo é dominado pela ideia de uma distinção a ser feita entre a coisa mesma e os simulacros”. A diferença é subordinada ao modelo, à noção da identidade e deixa de ser pensada como algo em "si mesma". Desse modo, reverter o platonismo, para esse filosofo, significa: "recusar o primado de um original sobre a cópia, de um modelo 
sobre a imagem". Ao radicalizar o rompimento com uma imagem de pensamento centrado na representação, na identidade, Deleuze nos desafia a um movimento de pensar a educação - pensar entendido como um ato de criação - e não como um ato de refletir sobre a educação. Assim, nosso desafio é potencializar os movimentos, os pensamentos as cadências que povoam nossas aulas, mas que muitas vezes são calados e dispersados pelo auto volume dos refrãos proferidos pelos livros e pelos docentes (DELEUZE, 1988, p.71).

Nesse sentido, é preciso renovar o que entendemos por aula de matemática, ainda pautada na exposição de definições e na resolução de longas listas de exercícios, em que apenas se reproduzem procedimentos de exemplos apresentados pelo livro ou pelo professor. Neste modelo, estamos exercitando o que Deleuze (2006) de "recognição". Uma aula que fica no registro da repetição, do pensar o já pensado, de treinar o pensamento para pensar o já pensado, nos emaranha na armadilha da recognição, negando-nos a experiência do pensamento criativo. Na perspectiva apesentada por Deleuze, a aula deve ser um espaço-tempo em que se constitua pela proliferação da diferença, pelas experiências não programadas, pela emersão dos pensamentos não esperados e não adequados aos modelos. Enfim, onde se pudesse pensar o ainda não pensado. Seria isso possível? Mas, voltamos a perguntar: o que significa pensar?

Deluze, em Diferença e Repetição, afirma que o pressuposto de que todo mundo pensa leva-nos a presumir que todo mundo sabe, implicitamente, o que quer dizer pensar. Assim, diz esse autor:

\begin{abstract}
A forma mais geral da representação está, pois, no elemento de um senso comum como natureza reta e boa vontade (Eudoxo e ortodoxia). [...] Neste sentido, o pensamento conceitual filosófico tem como pressuposto implícito uma Imagem do pensamento, pré-filosófica e natural, tirada do elemento puro do senso comum. Segundo esta imagem, o pensamento está em afinidade com o verdadeiro, possui formalmente o verdadeiro e quer materialmente o verdadeiro. E é sobre esta imagem que cada um sabe, que se presume que cada um saiba o que significa pensar. (Deleuze, 2006, p.129).
\end{abstract}

Nessa perspectiva, pensar é indicado como algo que naturalmente exercemos, algo que faz parte do senso comum e por ser "comum" podemos reconhecer. Logo, pensamos por que reconhecemos o conhecido. Poderia esse raciocínio justificar porque grande parte do tempo das aulas ou do tempo de estudo da matemática é reservado para resolver longas listas de exercícios “iguais"? Afinal, ao fazer repetidamente a resolução desses exercícios semelhantes o estudante estaria e supostamente está aprendendo essa ciência e desenvolvendo o pensamento matemático. (Monteiro; Mendes, 2018, p. 17).

Entretanto, Deleuze e Guattari, em O que é a Filosofia?, ressaltam a necessidade de problematizar essa naturalidade atribuída ao ato de pensar. Negando tal naturalidade, esses autores afirmam:

Pensar [...] é um exercício perigoso. [...] é sempre seguir a linha de fuga do voo da bruxa. [...] não pensamos sem nos tornarmos outra coisa, algo que não pensa, um bicho, um vegetal, uma molécula, uma partícula, que retornam sobre o pensamento e o relançam (DELEUZE; GUATTARI, 1992, p. 58-59). 
Enfim, são diversas as obras em que Deleuze - sozinho ou na companhia de Guattari - enfatiza a não naturalidade do ato de pensar. Com isso, ele se coloca na contramão da tradição filosófica, que pelo menos desde Aristóteles afirma que é da natureza do humano exercitar o pensamento, a racionalidade. Para Deleuze, ao contrário, o pensamento emerge de encontros e só ocorre, de fato, quando somos forçados a pensar. O encontro com signos nos afeta e nos mobiliza a pensar. Desse modo, aprender seria “tão-somente o intermediário entre não-saber e saber, a passagem viva de um ao outro" (DELEUZE, 2006, p. 238). Nesse mesmo sentido Gallo (2012) afirma que:

[...] aprender é sempre encontrar-se com o outro, com o diferente, a invenção de novas possibilidades; o aprender é o avesso da reprodução do mesmo. [...] isso se dá porque se aprender é relacionar-se com signos, eles, como problemas, pedem uma resposta e esta é sempre singular, inovadora. Cada um reage aos signos de uma maneira; cada um produz algo diferente na sua relação com os signos, o que equivale a dizer que cada um aprende de uma maneira, a seu modo singular. (Gallo 2012, p.8).

Logo, é preciso ousar e apostar em outras possibilidades educacionais, bem como buscar outras ferramentas que nos impulsionem a pensar. Segundo Deleuze (2006, p. 46) "há no mundo alguma coisa que força a pensar. Este algo é o objeto de um encontro fundamental e não de uma recognição”. E o que questionamos aqui é se a sala de aula, em especial se a aula de matemática pode ser um espaço de possibilidades no qual esses encontros podem se descortinar. Se sim, nosso desafio parece ser o de permitir outros movimentos, outras intensidades, permitir ao pensamento percorrer caminhos não mapeados, caminhos inventivos, instaurador de percursos impensados. Cabe, assim, tensionarmos os modelos propondo outras dobras, outras linhas de subjetivação. Mas o que isso significa?

Deleuze (1998), ao discutir sobre a imagem dogmática, refere-se a ela como detentora de três teses essenciais, que atendem às prerrogativas de muitos dos discursos sobre o conhecimento matemático, são eles: (i) a veracidade do pensador que ama o verdadeiro; (ii) o inatismo da ideia, do a priori dos conceitos, o que leva à naturalização do ato de pensar e, (iii) a tese que garante ao método o processo suficiente para se pensar bem, para se pensar verdadeiramente.

Nesse cenário, para muitos matemáticos e professores, a aula deve garantir a transmissão do conhecimento científico, verdadeiro e universal. Ou seja, é preciso treinar os alunos para reproduzir o modelo da ciência verdadeira. Para cumprir essa tarefa, por sua vez, o professor precisa ser um profundo conhecedor das verdades matemáticas e ter competência técnica para uma docência focada em avaliar e garantir que o modelo não seja corrompido. Uma vez que, a violação do modelo gera o que se considera erro e este deve ser evitado, apesar de poder ser explorado, em alguns casos, com fins de correção. Mas, se pensar fora do modelo pré-definido é algo que deve ser descartado, como explorar o não pensado? Como experimentar a criatividade no pensamento?

Falando de sua atividade como professor, Deleuze (1998) evidenciou a necessidade da preparação, como já comentamos, mas também afirmou que não há métodos ou receitas para esta preparação, que depende sempre das experimentações e singularidades de cada professor. Ele também 
afirma que "quanto mais alguém se enganou em sua vida, mais ele dá lições” (1998, p. 16), evidenciando que é no erro, no engano, no desvio que aprendemos aquilo que podemos ensinar. $\mathrm{O}$ erro, a experiência do erro, abre as portas para o pensamento criativo, que não opera fora da lógica ensaio-erro.

Cabe aqui nos voltamos a outro conceito explorado por Deleuze em sua obra Lógica do Sentido (1974), o Simulacro. Neste livro aparece como anexo um texto escrito anos antes, intitulado Platão e o Simulacro, e nele argumenta que

O platonismo é a Odisseia filosófica; a dialética platônica não é uma dialética da contradição nem da contrariedade, mas uma dialética da rivalidade (amphisbetesis), uma dialética dos rivais ou dos pretendentes. A essência da divisão não aparece em largura, na determinação das espécies de um gênero, mas em profundidade, na seleção da linhagem. Filtrar as pretensões, distinguir o verdadeiro pretendente dos falsos. [...] o mito não interrompe nada; ele é, ao contrário, elemento integrante da própria divisão. (DELEUZE, 1974, p. 260).

Ou seja, ao considerar a filosofia de Platão marcada não pela contradição, mas pela rivalidade, por certa competição entre dualismos, tais como: a Ideia e a imagem, o original e a cópia, o modelo e o simulacro, Deluze defende que Platão dividiria as cópias que constituem o mundo em dois tipos: as revestidas de semelhança, bem fundamentadas, consideradas como boas cópias; e em um outro grupo estariam signos de objetos constituídos pela dessemelhança, os simulacros-fantasmas, maus pretendentes, pois carecem de semelhança. Ele reforça assim a diferença de natureza entre simulacro e cópia. Ou seja:

A cópia é uma imagem dotada de semelhança, o simulacro, uma imagem sem semelhança. O catecismo, tão inspirado no platonismo, familiarizou-se com esta noção: Deus fez o homem à sua imagem e semelhança, mas, pelo pecado, o homem perdeu a semelhança embora conservasse a imagem. Tornamo-nos simulacros, perdemos a existência moral para entrarmos na existência estética. A observação do catecismo tem a vantagem de enfatizar o caráter demoníaco do simulacro. [...] O simulacro é construído sobre uma disparidade, sobre uma diferença, ele interioriza uma dissimilitude. (DELEUZE, 1974, p. 263)

Uma boa cópia não é algo exterior, pois trata-se de um processo de conformação, de identificação com objeto ideal pretendido na medida em que é uma busca para modelar a cópia a partir da Ideia, proporcionando uma certa escala de similitude. A melhor cópia será aquela que se mostre mais leal à reprodução da Ideia que se pretende modelar. O simulacro, por sua vez, é constituído de dissimilitude, portanto algo que é excluído da própria Ideia, logo trata-se daquilo que não tem a pretensão de ser copiado. Ou seja:

É a Ideia que desempenha o papel de fundamento por possuir, em primeiro lugar e de modo flagrante, uma qualidade que cada fenômeno só pode pretender possuir em segundo lugar, em terceiro etc., tendo em vista uma semelhança com ela. Assim, o "Mesmo" da ideia permite julgar os fenômenos, isto é, reparti-los numa escala eletiva, em proporção à sua semelhança ou conformidade interna com a Ideia concebida como modelo. $\mathrm{O}$ fundamento estabelece uma hierarquia entre os pretendentes a partir do modo como cada um representa a ideia. "Cada imagem ou pretensão bem fundada chama-se representação (ícone), pois a primeira em sua ordem é ainda a segunda em si, em relação ao fundamento. É neste sentido que a Ideia inaugura ou funda o mundo da representação (LAPOUJADE, 2015, p. 48). 
Mas do que se trata então o Simulacro? O simulacro não tem pretensão a ser modelo, a produzir cópias por não se incluir no rol dos fundamentos. Trata-se, segundo Lapoujade (2015), de aberrações, algo que se constrói sobre uma dissimilitude interna que contesta a legitimidade da ideia e do círculo que ela forma com seus pretendes. Conforme afirma Deleuze:

O simulacro: aquilo a que pretendem o objeto, a qualidade, etc., pretendem-no por baixo do pano, graças a uma agressão, a uma insinuação, a uma subversão, "contra o pai” e sem passar pela ideia. Pretensão não fundada, que recobre uma dessemelhança interna, assim como um desequilíbrio interno (DELEUZE, 1974, p. 263).

Logo, se a cópia se constitui numa imagem por semelhança, o simulacro, por sua vez, se constitui pelo desvio, por uma imagem ausente de semelhança. Ele [o simulacro] não tem pretensão de se referenciar a um modelo pré-definido. Para a filosofia da representação, essa condição do simulacro é vista como algo negativo, como algo improdutivo, afinal ele se afasta da verdade que a semelhança proporciona. Portanto, deve ser evitado, excluído (MONTEIRO; MENDES, 2019).

Assim, ao se considerar a matemática escolar e acadêmica como um conhecimento verdadeiro e universal, seu ensino deverá se ocupar em garantir boas cópias, o que significaria um ensino focado na transmissão de proposições verdadeiras, um ensino que minimizasse as más cópias, o que justificaria a ocupação de grande parte do tempo focado nas formas: formas de resolver, formas de escrever, formas de pensar. Trata-se de garantir a ordem, de cumprir os pactos procedimentais, de seguir o método para salvaguardar a boa cópia, o bom modelo (MONTEIRO; MENDES, 2019).

Como reverter essa lógica? De que modo fazer emergir simulacros? Percebam que advogar por simulacros não significa defender um ensino de proposições falsas, pois isso seria apenas inverter o processo. Mais do que isso, o desafio é explorar os desvios. Trata-se de um deslocamento conceitual. Deslocamento esse que corrobora com o que propõe Gallo (2003), ou seja, "trata-se de caminhar nas incertezas, nas multiplicidades Trata-se de trocar a zona controlada pela zona das trincheiras" (GALLO, 2003, p. 21).

Em um diálogo com a jornalista Claire Parnet, Deleuze (1998, p. 16) afirmou que "Professor, gostaria de conseguir dar uma aula como Dylan organiza uma canção, surpreendente produtor, mais que autor". O filósofo comenta o modo criativo do cantor e compositor estadunidense, que consiste em ir juntando cacos obtidos em suas experiências pelo mundo, para depois montá-los criativamente, como quem brinca com um jogo de armar, produzindo novas estruturas a partir de blocos. Por isso sua afirmação de ser "mais produtor do que autor". O professor é o produtor de uma aula, juntando elementos para compor a matéria de seu ensino; mas o jogo de armar pode se tornar coletivo, se os estudantes forem convidados para trabalhar junto, promovendo e celebrando o encontro, numa criação coletiva. 
O conceito de “educação menor" proposto por Gallo (2002, 2010, 2013a, 2013b) considera que inúmeros e diferentes desvios emergem nos e dos contextos escolares todos os dias, mas na maioria das vezes são imperceptíveis pela insensibilidade que o modelo de uma "educação maior", centrada na execução correta de um saber universal e inequívoco, produz. O programa já foi cumprido? Todos aprenderam a forma correta de realizar as atividades? Esta é a pergunta persecutória da sala de aula.

Nesse sentido, o conceito da "educação menor" nos convida a experimentar outro modo de estar na sala de aula, no qual sujeitos assumem situações coletivas que lhes permitem produzir a possibilidade do novo. Assim, eles nos desafiam a trabalhar em uma relativa liberdade de escolha, que não acontece previamente, mas pode ser criada, inventada a partir da imprevisibilidade de encontros, da singularidade de acontecimentos que atravessam o espaço escolar e afetam professores e alunos (GALLO, 2003). Nesse mesmo sentido Mate (2013) destaca a ideia da singularização coletiva. Para essa autora:

$\mathrm{Na}$ educação menor se todos se descobrem indivíduos, o fazem de modo coletivo. [...] o trabalho coletivo do professor com sua classe passa a ser o de cumplicidade. Ele se descobre professor quando, junto com seus alunos, ajuda-os a se perceberem em suas multiplicidades e possibilidades. E isso se dá no grupo, na classe, com as experiências se manifestando e se deixando conectar umas às outras, e nessa interligação, as singularizações se dão, se movimentam, sempre coletivamente. (MATE, 2013, p. 2).

Nesse sentido, na perspectiva da educação menor a aula se desdobra como acontecimento, com e inúmeros desvios. Desvios que são capturados. Mas é no instante do imprevisto, do improviso que encontros potentes atravessados por desejos e afetos são possíveis. Serres (2003) apresenta a ideia de desvio por meio do conceito de Clinâmen, isto é, "o ângulo de formação de um turbilhão, aparecendo aleatoriamente em um fluxo laminar" (SERRES, 2003, p. 17). "É um diferencial, é aquilo que na turbulência dos pontos (corpos como pontos deambulantes - móveis no espaço) faz diferir; ele não cessa, (...) é a velocidade" (SERRES, 2003, p. 232).

Portanto, os desvios ao se formarem por meio do turbilhão, do caos, se desviam tangencialmente, criando linhas de fuga potentes, cujas forças nos afetam e nos deslocam. Inúmeros de fato vão se perder. No entanto, o que podemos fazer para potencializá-los? Como já citado anteriormente, Deleuze diz que nunca poderemos saber em que nossas aulas podem afetar o outro. Por isso é preciso ouvir. É preciso ruminar! É preciso viajar. A seguir apresentamos duas cenas que têm por objetivo apenas nos provocar a pensar em torno de nossa função-professor.

Cena 1: Tratava-se de uma aula de matemática em que os alunos faziam a correção das conversões de medida: 1000 metros equivalem a $1 \mathrm{Km}$. A professora explicava as conversões durante a correção de uma lista de exercícios presente no livro didático. Muitos dos alunos pedem à professora para ir mais devagar, pois precisam apagar e refazer a lição - ou seja, corrigir os erros, as cópias malfeitas. De algum modo, ao resolver as atividades, as crianças escaparam do modelo de resolução proposto. Nesse contexto um aluno distraído olha para a janela. A professora me pede para me aproximar e ajudá-lo. Trata-se de um aluno considerado com dificuldades de aprendizagem. Carrego minha cadeira e peço para me sentar 
ao seu lado. Ele diz que sim. Senta-se voltado para a lousa e pega a caneta. Seu corpo fala. Seu corpo me avisa que passará a ficar atento ao que se espera de um bom aluno. Atenção! Percebo que ele não corrigiu sua lição e que havia feito apenas o início. Pergunto se ele quer ajuda e ele me diz:

-Não pro! Eu nem sei começar a fazer isso. Deixa pra lá.

Eu digo ok. E pergunto o que está acontecendo fora da sala, pois ele estava olhando para a janela. E ele me responde:

- Estava? Nem percebi. Eu estava pensando em viajar. A Pro. M (professora da turma) disse que pra chegar na praia tinha muitos quilômetros. Sabe, eu nunca fui na praia. Você já foi? Como é a água? É salgada mesmo? A água se movimenta sozinha?

Em um lapso de segundos a professora comentou da distância entre a cidade de Campinas e uma praia paulista. Apenas para mostrar que usar metros em vez de quilômetros não seria algo adequado. Entretanto foram esses segundos que tocaram esse aluno. Foram eles que, como o canto de um sabiá, o acordaram para o sonho, o de visitar a praia. Trata-se de um sonho. Não de algo que resiste à aula, mas trata-se de um encontro, de um momento, de um modo de estar lá, antes do encontro com esse "lá". Poderia uma aula de matemática mobilizar sonhos outros? Movimentos de águas, cheiros, gostos? De que aula estaríamos falando se, naquele momento, experimentássemos esse desvio? Qual a sua potência?

Cena 2: Esse caso já é bastante conhecido pelos educadores, mas vale a pena ser apresentado mais uma vez. Numa atividade de aula com os indígenas Suyá, Juruna e Kayabi, no Parque Indígena do Xingu, o problema matemático proposto foi: Ontem à noite peguei 10 peixes. Dei três para meu irmão. Quantos peixes tenho agora? No contexto da matemática acadêmica, trata-se de um simples problema de subtração 10 - 3 = 7. Porém a solução apresentada por Tarinu Juruna foi "13 peixes". Ele assim explicou seu raciocínio: "Fiquei com 13 peixes porque quando eu dou alguma coisa pra meu irmão, ele me paga de volta o dobro. Então, 3 mais 3 igual a 6 (o que o irmão lhe pagaria de volta); 10 mais 6 é igual a 16; e 16 menos 3 é igual a 13 (Ferreira, 1993, p. 39). Esse é um caso mais explícito da aberração, da falta de adequação ao modelo. "Algo que não se ensina apenas pode ser aprendido e não numa aula. Algo que precisa de vida, de experiência de vida para que possa ser considerado e compreendido",5 (CARVALHO, 2021).

O que se pode aprender numa aula de matemática?

As contribuições de Deleuze, além de desdobramentos propostos por outros autores, nos permitem destacar que os desvios, provocados por uma educação menor e militante, podem abrir espaços potentes para fazer o pensamento funcionar de outros modos, abrir possibilidades para novos encontros e com isso produzir novos e outros desvios e assim, de forma rizomática, colocar o modo controle e previsivel da reprodução em suspensão e nos colocar na posição de pensar sobre o que o nos dá a pensar. Afinal diz o filósofo: 'Uma aula é emoção. É tanto emoção quanto inteligência. Sem emoção, não há

\footnotetext{
${ }^{5}$ Considerações feitas pelo Professor Alexandre Filordi de Carvalho em aula, num outro contexto semelhante ao apresentado.
} 
nada, não há interesse algum”. (DELEUZE, 1987, p. 94) E ainda, em Prost e os Signos, ele afirma: [...] "Mais importante do que o pensamento é o que "dá que pensar"; "mais importante do que o filósofo é o poeta” (DELEUZE, 2003). De modo que, tendo iniciado o texto com uma música, que nos serviu de inspiração, o finalizamos como um poema de Manoel de Barros (1996), que nos serve como transpiração:

\title{
Retrato do artista quando coisa
}

\author{
A maior riqueza \\ do homem \\ é sua incompletude. \\ Nesse ponto \\ sou abastado. \\ Palavras que me aceitam \\ como sou \\ - eu não aceito. \\ Não aguento ser apenas \\ um sujeito que abre \\ portas, que puxa \\ válvulas, que olha o \\ relógio, que compra pão \\ às 6 da tarde, que vai \\ lá fora, que aponta lápis, \\ que vê a uva etc. etc. \\ Perdoai. Mas eu \\ preciso ser Outros. \\ Eu penso \\ renovar o homem \\ usando borboletas. \\ (Manoel de Barros)
}




\section{REFERÊNCIAS}

BARROS, Manoel. Retrato do artista quando coisa. Livro sobre Nada. São Paulo: Ed. Record, 2001. CARVALHO, Alexandre Filordi. Foucault e a função-educador. $2^{\mathrm{a}}$ ed. Ijuí: Editora Unijuí, 2014. DELEUZE, G. Lógica do Sentido. 2a. ed. Tradução de Luiz Roberto Salinas Fortes. São Paulo: Perspectiva, 1974. $2^{\circ}$. Edição

DELEUZE, G. Diferença e Repetição. 1a. ed. Tradução Luiz Orlandi, Roberto Machado. Rio de Janeiro: Graal, 1988.

DELEUZE, Gilles. Proust e os signos. 2. ed. Rio de Janeiro: Forense Universitária, 2003.

DELEUZE, G., PARNET, C. Abecedário de Gilles Deleuze. Éditions Montparnasse, Paris. Filmado em 1988-1989. Publicado em: 1995. Transcrição integral do vídeo, para fins exclusivamente didáticos. Disponível em: http://www.bibliotecanomade.com/2008/03/arquivo-para-download-o-abecedriode.html / Acesso em: 23 mar 2021.

DELEUZE, Gilles; GUATTARI, Felix. O que é a filosofia? Tradução de Bento Júnior e Alberto Alonso Muñoz. Rio de Janeiro: Ed. 34, 1992.

DELEUZE, Gilles; GUATTARI, Felix. Mil platôs: capitalismo e esquizofrenia. v. 5. Tradução de Aurélio Guerra e Célia Pinto Costa. Rio de Janeiro: Ed. 34, 1995.

DELEUZE, Gilles; PARNET, Claire. Diálogos. São Paulo: Escuta, 1998.

DRUCK, Suely. Desempenho da pesquisa em matemática não se reflete no ensino da disciplina, sobretudo nas escolas públicas. Entrevista ao Jornal da Universidade Estadual de Campinas - 14 a 27 de fevereiro de 2005. Campinas, 2005.

DRUCK, Suely. Quando a matemática deixou de ser o "bicho papão". Publicado por Denise Wasserman em 24 de junho de 2019 | categoria destaques. Disponível em: https://www.nosso.jor.br/quando-a-matematica-deixou-de-ser-o-bicho-papao/ Acesso em: 23 mar 2021.

FERREIRA, Mariana K.L. Quando $1+1$ é diferente de 2: Práticas Matemáticas no Parque Indígena do Xingu. In Cadernos de Campo. $\mathrm{N}^{\circ}$ 3. 1993. Disponível em: https://amerindias.github.io/referencias/fer93matematicaxingu.pdf Acesso em: 23 mar 2021.

GALLO, Silvio. Conhecimento, Transversalidade e currículo. In:

https://www.academia.edu/518339/Conhecimento_transversalidade_e_curr\%C3\%ADculo_s/d. Acesso em: 23 mar 2021

GALLO, Silvio. Em torno de uma Educação Menor. Educação \& Realidade, v. 27, n, 2, p. 169-178, jul./dez. 2002. Disponível em: https://seer.ufrgs.br/educacaoerealidade/article/view/25926/15194 Acesso em 23 mar 2021

GALLO, Silvio. As múltiplas dimensões do aprender... In: Congresso de Educação Básica - COEB: aprendizagem e currículo. Anais do... Florianópolis: COEB, 2012. Disponível em: 
$<$ http://www.pmf.sc.gov.br/arquivos/arquivos/pdf/13_02_2012_10.54.50.a0ac3b8a140676ef8ae0dbf 32e662762.pdf>. Acesso em: 23 mar 2021.

GALLO, Silvio. Filosofia da diferença e educação: o revezamento entre teoria e prática. In: ClARETO, Sônia Maria; FERRARI, Anderson (Orgs.). Foucault, Deleuze e Educação. Juiz de Fora: UFJF, 2010. p. 45-63.

GALLO, Silvio. Deleuze \& Educação. Belo Horizonte: Autêntica, 2013.

LAPOUJADE, D. Deleuze, os movimentos aberrantes. Tradução: Laymet Garcia dos Santos. São Paulo: n-1 edições, 2015.

MATE, Cecilia Hanna, A aula como acontecimento e o conceito de amizade na relação professor aluno. In Didática e Prática de Ensino na relação com a Escola. EdUECE. 2013. Disponível em: http://www.uece.br/endipe2014/ebooks/livro1/5-

\%20A\%20AULA\%20COMO\%20ACONTECIMENTO \%20E\%20O\%20CONCEITO\%20DE\%20A MIZADE\%20NA\%20RELA\%C3\%87\%C3\%83O\%20PROFESSOR\%20ALUNO.pdf s/d. Acesso em 23 mar 2021.

MONTEIRO Alexandrina; MENDES, Jackeline Rodrigues. Salas de aula como espaços de composições da diferença na formação docente. RECC, Canoas, v. 23, n. 1, p. 13-25, mar. 2018. Disponível em: https://revistas.unilasalle.edu.br/index.php/Educacao/article/view/4231/Acesso em: 23 mar 2021.

SERRES, Michel. O nascimento da física no texto de Lucrécio: Correntes e turbulências. Tradução Péricles Trevisan. São Paulo: Ed. UNESP. São Carlos: EdUFSCAR, 2003. 